\title{
Design of Next-generation Virtual Library for Free Movement in a 360-degree Perspective
}

\section{${ }^{1}$ Li Xuezhen, ${ }^{2}$ Fujimoto Takayuki Li}

\author{
${ }^{1}$ Ph.D Student, Toyo University, Japan \\ 2 Toyo University, Tokyo, Japan.
}

Article History:Received:11 november 2020; Accepted: 27 December 2020; Published online: 05 April 2021 \begin{abstract}
In this research, we design a virtual library that allows users to have a 360-degree perspective and move freely. We will focus on the function of the library not only as 'a public facility for lending books' but also as 'a place for encountering new knowledge by accident.' In modern open-stack libraries, the function of 'a place for encountering new knowledge by accident' is realized through the act of 'walking around'. However, regarding the online libraries and digital libraries, which have been rapidly developing in recent years, they offer scarce functionality of 'encountering unknown knowledge by accident' by 'walking around in the library', while increasing convenience through digitization.In light of this problem, this paper devises a virtual library equipped with the function that users can move freely in the library in a 360-degree view'. By providing the state of bookshelves and books which are on display by actual $360^{\circ}$ videos rather than artifacts such as $\mathrm{CG}$ or animation, users can acquire necessary related information of books while having the realistic experience of being in the library. Past digital libraries are reproductions of libraries as building structures, and the libraries' original function of encountering books and knowledge was low. On the contrary, as for the online libraries, users can only search for book information, and cannot obtain the sense of being in the library. This study proposes a new virtual library that combines past digital library and online library.
\end{abstract}

Keywords: virtual space, online library, 360-camera, library space.

\section{BACKground AND Purpose}

In recent years, with the development of the Internet, online libraries have become more and more popular. Even though they are all called as 'online library', there are various designs. The simplest is the one that you can search the collections of libraries and browse the contents online. Although some of the services are not free, this style is globally available in online bookstores such as Kindle and Amazon.

A system that can search the collections of libraries and browse the content online has already been realized on a global level with the advent of world class-online bookstores. Therefore, when we talk about future libraries, it is very important to focus on how libraries are going online and this issue gathers people's attention..

In recent years, public libraries and university libraries do not just provide the service of searching collections of books on websites, they also have the digitized part of the collection that users can browse online. For example, the National Diet Library in Japan publishes some rare books in their collection and classical books that are out of copyright as digital archives for free. The number of such cases has increased rapidly in recent years, especially among famous libraries worldwide, and it is increasing the convenience for researchers.

As the style of future's libraries, not only focusing on utilization of the books collection but also digitizing the library itself and making it open to the public see a sudden increase in recent years. There are many cases that provide the functions where virtual tours of libraries can be experienced online, or offer new use experiences of libraries by using VR and 3D systems.

In this way, libraries today are exploring the new library style in the Internet age by effectively using VR and 3DCG's environments. However, many of the functions of online libraries other than Online Public Access Catalogue(OPAC), are just advertising expressions or entertainment. Even if the library is reproduced by VR or experiences to use facilities or books are recreated by 3DCG, the library's original purpose: 'stroll through bookshelves, search and browse books" to encounter unknown knowledge is hardly satisfied.

In other words, many of today's virtual libraries are just 'virtualization of building structures, which are called libraries', and they are not 'virtualization of library function where people come to encounter knowledge'.

Therefore, in this research, we design a new virtual library with practicality that fuses library collections with library space for "virtualization of the library function to encourage people to encounter unknown knowledge ". In this paper, we particularly focus on one of the major needs from library users, "walking through bookshelves, while searching and browsing books', and propose the concrete mechanism to realize that virtually.

Due to covid-19, since 2020, many libraries were closed, and it reduced the number of opportunities to 'encounter new knowledge by chance' through mediums like libraries. Through this research, we would like to use 
this lack as an opportunity to reconsider the function of virtual libraries and the direction of future development. Fig. 1. Magnetization as a function of applied field.

Fig. 1. visual space of the British Museum.

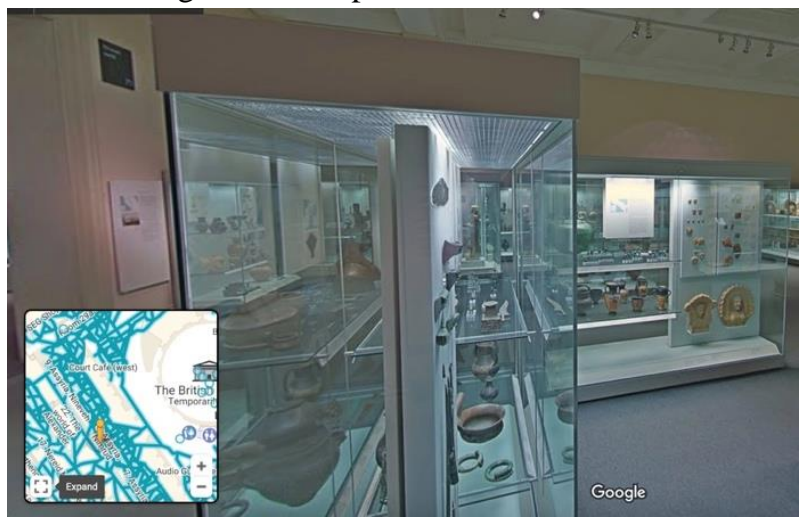

\section{RELATED RESEARCH}

In this chapter, we describe the previous examples of online public facilities such as museums and stadiums with free movement functions in virtual spaces and related research on user movement information in libraries from two aspects, practicability and theory.

A. Cases of online public facilities in which people can move freely

\section{Online space built with CG animation}

These days, AR and VR technologies have been actively used in various industries such as games, concerts, and sports broadcasts in order to improve the audience's 'real feel'.Particularly since 2020, the coronavirus crisis has made it difficult to hold face-to-face events, and many entertainment industries are using such technology to enhance the 'live reality' of online events.

For example, KDDI, a Japanese telecommunications company, hosts events such as baseball games' broadcasts, school festivals, and sightseeing online, users (participants) can move freely around event venues in virtual spaces simulating reality using VR devices and avatars. The event venue in the virtual space also offers a different priority from existing online events, with functions such as virtual stores where users can actually shop and entertainers, who are coming out as avatars. Users can also create their own virtual worlds using Unity and the Cluster Creator Kit .

Being able to participate in events in virtual space via using avatars and move freely around the facilities, is more realistic experience than just watching video of events. It is the significant advantages of this kind of virtual space. However, the point that who is at the event venue is not yourself, but the avatar can dilute the user's 'sense of reality' of participating in events, and sometimes it can be disadvantage that gives the user a feeling of emptiness. Even with current technology, no matter how realistic the virtual space is, the 'awareness of that it is unreal' still remains.

\section{Online space built with photographs}

With the development of digital archiving technology, there are more art museums and museums where you can view the collection of masterpieces online. The most famous one is the British Museum's online service(Fig.1). Photos of almost all exhibits are in public on the British Museum homepage. In addition, via using Google Arts\&Culture service users can see the entire interior of the museum, including exhibition cases and descriptions. The 360-degree photos (still images) used here, instead of CG. Therefore, it gives users a more realistic experience than the space built with CG animation.

Moving mechanism in virtual space is similar to Google Street View, through continuously pasted 360-degree photos on a map, you can move freely inside of the building, albeit with still images. Like Google Street View, it is linked to a map, letting users know their location easier. However, pasted photos of 360-degree still images on the map can just provide a simulated sense of moving, which is always like 'teleportation', and natural walking movement is impossible. In addition, it is not possible to go to the place where is not assigned to the map. Virtual space built with 360-degree photography is more realistic than CG animation, but expression by still images also has its limitation. There are still many problems to be solved in combining the reality of space with the sensation of actual walking movement. 


\section{B. Studies on user information in library}

\section{Cases regarding the user movement in library}

Many of the basic researches to collect information on user movement in libraries are for examination and improvement of technical problems. For example, Ogawa et al. (2012) collected user movement information by sensors attached to users and analyzed them with high recognition accuracy by using matching of label sequence data.

In an experiment conducted by Toyota et al. (2018), the subjects moved around in library while holding a smartphone dedicated to the experiment and searched for specified documents.By sending a signal with BLE beacon set in the library and receiving a signal with the application installed on smartphone, the subject's movement trajectory and amount of time to find the documents were recorded, and thus the usage situation was grasped by this way.

Fukami (2020) clarified the effect of measurement accuracy by verifying antenna placement and angle regarding collecting user behavior information in libraries using IC tags.

\section{Analysis of library users}

Okamoto et al. (2017) conducted a survey on the use of documents in library for two years using a Radio Frequency Identification (RFID) system. Compared to the number of out-library loans, the frequency of taking out from bookshelves inside library was about three times, and it was confirmed that the major library usage was 'stand and read' use in 2 to 4 minutes rather than bringing books to the reading seat. It was clarified that the casual uses of books in the library has a big demand. Regarding the use of coming to the library to search for the specific books, there are many people who finally found no necessity to rent books out of library: browsing the books inside the library was enough, when they actually spread pages of the books.

According to data from Sugie's (2012) experiment at Chiyoda Library, the range of one user's movement is $25 \%$ of the library area when he or she enters the library once, regardless of whether they come with purpose or not. Therefore, it was suggested that 'moving around the library' is important factor for people when using the library.

From these, only when users can walk between bookshelves and freely spread the pages of the books that grabbed their interests, as well as they can in the actual libraries, it can be said that they are in the ideal virtual library.

\section{Characteristics OF LIBRARY SPACE}

A. Movement in library and accumulation of knowledge

Libraries have the role of "for accumulation and use of knowledge.". But from the user's perspective, the most outstanding function is they allow users to 'encounter with new knowledge by chance: accumulation of knowledge' and this feature cannot be found in other knowledge spaces and databases. The main component of open-stack libraries are bookshelves and books lined up on bookshelves. When users walk around the library to look for books, they are irresistibly sandwiched in the bookshelves on both sides of the aisle, and various books (knowledge) other than the books that they are aiming for, inevitably come into their views, even if they have nothing to do with what the users are looking for. Such movement in the library (between bookshelves) is not only a means of transportation to the destination, but also an important function for encountering books and knowledge that are not originally expected in the library. Librarian Antonella Agnoli wrote when describing the need for public space:

"When we catch sight of the urban environment, it's usually when we are moving. For example, you go through a public space when go to somewhere. Or you can just take a walk. Anyway, we use it while moving. What this means is that we have a partial and progressive view of it"

In a word, human sees the space inevitably through the act of 'Walking', and encounter knowledge and information at that time. That is why it is easy to discover something new through the act of walking around. In that sense, most online and digital libraries today, which do not have the function of 'walking around freely', completely lack the function of 'accumulation of knowledge', which is a part of the library role: "for accumulation and use of knowledge". Therefore, the function with which the user can walk around freely in the library is required for the virtual library in the future.

\section{B. The "rhythm" of bookshelves and books arranged in library}

From the viewpoint of architecture and urban sociology, library space seems to be a suitable place for 'encountering with new knowledge by chance: accumulation of knowledge'.

The movement of going through between the bookshelves filled with books is a pleasant experience not only for the user who browses the library without the clear purpose but also for the

user who goes to the specific bookshelves according to the call number. P.F. Smith says that libraries have spatial elements - the rhythm and order of visual composition - that are easy to sense aesthetics. Indeed, a library filled with bookshelves is rather crowded to walk, but the books lined up there are not 'disturbing obstacles' but 'pleasant obstacles'. 
The bookshelves that occupy the major area of the library have a great influence on the overall style of the library. Library books are displayed in an orderly manner on bookshelves and presented to users in accordance with a certain classification (currently widely used in Japanese libraries is Nippon Decimal Classification (NDC)). Library bookshelves are generally organized according to classification and arranged at equidistant along straight lines (or walls) in the building. Of course, the style and organization of the bookshelves may be customized for the convenience of users. For example, in regards to a children's reading room, the total length of the bookshelves is set lower. Although the overall style of the bookshelves is uniformed, each area is adjusted according to its function and role, and it results in avoiding monotony.

In addition, because the magazines and the newspapers cannot be arranged like usual books, bookshelves for open-display are used for them. Books arranged in uniform straight lines on the bookshelves balance order and change by various sizes, shapes, and covers.

The way with which books and bookshelves are displayed has not only a functional role, but also an aesthetic value. Whereas traditional online libraries are functional for information search, they do not have aesthetic value as libraries. In order to realize a realistic virtual library, it is also important to focus on the "rhythm" inside the library.

\section{THE DESIGN IF MECHANISMS}

We designed a virtual library that provides users with the sensation of moving in the library: the realistic library experience, by using 360-degree real images. It focuses on the journey experience upon which the user can walk through between the bookshelves that filled with books from the starting point to the destination. The user's vision always reflects the bookshelves and the books, and the encounter with the unexpected knowledge by accident occurs inevitably, whether the user is conscious or unconscious of seeing them.

\section{A. Representation of virtual space by 360-degree videos}

There are many virtual space systems that provide a 360-degree field of view. It is frequently used not only for libraries but also for real estate guidance and introduction of buildings, and in recent years, its practical application has progressed. These existing virtual space systems use images (still images) taken in all directions of 360 degrees, and they can provide flat virtual space only as a motionless scene. Google Street View and others are designed to continuously connect the 360 degrees images to a map so that the entire map feels 360 degrees. However, the images are nothing more than photographs taken at 360 degrees as the flat still images.

In contrast, the virtual library proposed in this study uses 'video' instead of 360-degree photographs (still images) to increase the sensation of immersion.

We designed a system that allows users to move in the virtual library in their own way using videos of the actual library instead of artificial content such as avatars and CG.

In addition to reproducing the inside of the library building and facilities, all of the placed bookshelves and books arranged there are represented with 360-degree images.

B. Free movements by users

As mentioned in the previous section, the image is taken while actually moving between the bookshelves using a 360-degree camera, and the bookshelves are divided into each bookshelf as a unit. Instead of replaying the completed '360-degree documentary on the inside of the library' like a movie or Youtube video, users can freely select a bookshelf (unit category) and move around the bookshelf by watching the video.

When moving between actual bookshelves, the center of the bookshelf is usually the most noticeable, and the top and bottom are easy to be overlooked. In order to reproduce this feature, the position of the camera (position of the line of sight) is fixed to the same as the height of the general user's line of sight.

C. Controlling the user's free movement by actual walking operation

Conventional digital libraries are usually provided in the form of website or application content, and they are operated with a mouse or a hand, just like using websites and applications. Like 3D games, it is a method of exploring the library using a mouse or keyboard, and while there is an advantage that users are familiar with the method, it cannot provide sense as if the users were in the actual libraries. Rather than browsing around the library, it feels more like looking at a 3D game's website or nothing but using an application.

Therefore, we implement a system that requires users' actual action of 'walking' to move around in the virtual library.The playback of 360 degrees video of the library is controlled by user's actual walking while holding a smartphone that has the installed system..In this system, 360 degrees video playback begins when the user starts walking while holding the smartphone and looking at its screen.

The playback speed of the 360 degrees video changes according to the user's walking speed. If the user stops walking, the video will also stop playing. You can watch the library with 360 degrees vision while on the moving or stopped. In short, the change of playback speed of a 360 degrees video is not fixed by selection such as 1.25 times or 0.75 times as fast, instead, the playback speed varies depending on the speed at which the user is actually walking at the time of use. 


\section{Providing bibliographic information of books}

When a user finds a book of interest as they move between bookshelves in this virtual library, they can click or touch the spine to 'open the book spread' for the same effect as opening a paper book. Not only does this reproduce the action of 'spreading the book', but it also allows you to get the relevant information to this book.It is possible to obtain the bibliographic information, which is equivalent to that acquired when people hold and open a paper book. The information available to the user here is general bibliographic information that the library has given to each book (author name, publication year, publisher, International Standard Book Number (ISBN), outline of contents, and etc.).

In addition, in libraries, usually there is advice or reference service by librarians when users search for books in the fields where they do not have much knowledge. However, past online libraries or book search systems do not have such a function. Therefore, regarding the system proposed in this study, we plan to provide AI reference service that proposes related books the user may not know by interrelating book information. The AI reference service can propose the books by the same author or the author, who has involvement with him or her, books borrowed by other readers who had ever used the same book, and recommendation based on online book reviews.

\section{SUMmary AND FUTURE WORKS}

In this paper, regarding the style of virtual library in the future, we examined the cases of the existing online libraries and virtual facilities and clarified their problems. Thence, we designed a specific mechanism for the virtual library that enable users to "move freely" using realistic 360-degree videos. By constructing a digital library as virtual space, it can change from a flat online library website to a three-dimensional visual space, functioning as a place to explore and discover knowledge.

By using the 360-degree video and a video control application based on 'actual walking movements', we reproduced the library experience to the maximum to increase the users' sense of immersion.

Future issues include improving the clarity of 360-degree images and optimizing the accuracy of walking speed control. Besides, we will also realize the user's selection of the book by gestures without mouse or touchpad, and explore the further possibility to release the user from the direct terminal operations.

\section{REFERENCES}

Kuniko. Hisamatsu, “特集：「家具 一図書館を支える脇役たち一」の編集にあたつて,” The journal of Information Science and Technology, vol. 70-2, pp. 51, February 2020.

Henry Petroski, The Book on the Bookshelf, Japan: Hakusuisha, 2004.

Antonella Agnoli, Le Piazze del Sapere, Japan: Mizusu Shobo,2017.

Kazushi. Okamoto, Hikaru. Kazama, Kazuhiko kawamoto, "A fuzzy codebook based image search method for visual localization in libraries," 28th Fuzzy System Symposium, pp.444-447, July 2012.

Sho. Sato, Hiromichi. Ito, “図書の書架上の位置が利用者の注視時間に与える影響,”, Journal of Japan Society of Library and Information Science, vol.66-2, pp.55-68, June 2020.

Kazushi. Okamoto, Rie. Marumo, Haruka. Sano, "In-Library Book Usage Survey by using Radio-Frequency Identification System Installed Bookshelves," Journal of Japan Society of Information and Knowledge, pp.227-244, 2017.

Yukinori. Okabe, 才能を引き出した情報空間, Japan: Bensei Publishing, 2017.

Kazuhiko. Mashiko, 図書館空間のデザイン-デジタル化社会の知の蓄積, Japan: Maruzen Publishing, 2011.

Ryo. Akama, Keiko. Suzuki, Kozaburo. Hachimura, Yano. Keiji, Toshihiko. Yuasa, 文化情報学ガイドブック, Japan: Bensei Publishing, 2014.

Nanako. Tkahashi, "Virtual space for library services : online morning reading room and digital bookshelf gallery at Tokyo Gakugei University," The Library journal, vol.114, pp.617-619, 2020.

P. F.Smith, "Urban Aesthetics,"Architecture for People: Explorations in a New Humane Environment, London: Studio Vista, 1980. 